\title{
TEATRO ITINERANTE: ESPAÇO DA MEMÓRIA E DA CULTURA POPULARES - 0 TEATRO DE LONA SERELEPE
}

Elaine dos Santos ${ }^{1}$

\begin{abstract}
Resumo: 0 presente trabalho constitui um estudo introdutório a respeito do teatro itinerante, seu desenvolvimento na civilização ocidental, dando-se ênfase a sua presença na cultura brasileira, em especial gaúcha, considerando-se, para tal, a história do Teatro Serelepe. Teatro cuja história inicia-se no interior paulista, em 1929, e acompanha as transformações vividas pela nossa sociedade, incluindo o período ditatorial, posterior a 1964 e que foi marcado pelo cerceamento da liberdade. Procura-se estabelecer relações entre o teatro itinerante e a conservação e a transmissão da memória popular do país para, ao final, salientar-se a importância daqueles saltimbancos que percorrem o nosso território e levam alegria à população mais humilde.

Palavras-Chave: Memória popular, Teatro itinerante, Teatro Serelepe.
\end{abstract}

\begin{abstract}
The present work constitutes an introductory study of itinerant theater and its development in western civilization, emphasizing its presence in Brazilian (particularly gaucho) culture, focusing - to this end - on the history of the Teatro Serelepe. The history of this theatre group begins in the countryside of São Paulo in 1929, continuing through periods of social transformation including the dictatorship following 1964, a period characterized by serious restrictions on liberty. The work aims to establish the relations between the itinerant theater and the conservation and transmission of the country's popular memory, emphasizing the importance of the performers who traveled these territories bringing joy to the poorest people.

Key Words: Popular memory, Itinerant theater, Theater Serelepe.
\end{abstract}

\section{INTRODUÇÃO}

Este trabalho, estudo introdutório acerca do teatro mambembe no Rio Grande do Sul, propõe-se, em seu final, identificar os elementos que constituem a memória preservada pela comédia de cunho popular, discutir as influências do referido teatro na construção do imaginário social e recompor a história dos teatros itinerantes no estado mais meridional do país. Para a consecução destes objetivos, a pesquisa bibliográfica, as entrevistas in loco e os registros disponíveis nas diversas companhias de teatro mambembe ainda em ação no estado são elementos fundamentais. Lida-se, neste ponto, com memórias familiares, histórias de vida e, em conseqüência, com as emoções daqueles que recordam. Neste sentido, faz-se pertinente recompor, do ponto

1 M estre em Estudos literários pela Universidade Federal de Santa M aria - UFSM; docente do curso de Letras da Universidade Luterana do Brasil - ULBRA, Campus Cachoeira do Sul (RS). Endereço eletrônico: e.kilian@gmail.com. 
de vista teórico, os estudos acerca do fenômeno mnêmico para, a partir dele, empreender as pesquisas de cunho histórico.

Nesta primeira etapa, seleciona-se para estudo o Teatro de Lona Serelepe que, desde 1962, percorre o interior gaúcho e que, nas figuras de José Maria de Almeida, o velho Serelepe, e Lea Benvenuto de Almeida, mantém a memória viva do teatro mambembe em nosso estado. Apresenta-se, neste trabalho, além da evolução da memória e as formas como se processa a recordação dos eventos individuais e coletivos, uma breve história do teatro mambembe e, em especial, do Teatro de Lona Serelepe, foco inicial da pesquisa, para, ao final, tecer-se as primeiras considerações sobre 0 assunto.

\section{A MEMÓRIA}

A memória, no transcurso da história humana, sempre despertou curiosidade: Como lembramos? Porque lembramos? 0 que lembramos e como acontece a seleção destas lembranças? Há registros que, entre os gregos da época arcaica, concedeu-se significativa importância ao fenômeno mnêmico de tal sorte que se instituiu uma deusa, Mnemosine. Le Goff (1996, p. 438) anota que a deusa "lembra aos homens a recordação dos heróis e dos altos feitos, preside a poesia lírica. 0 poeta é pois um homem possuído pela memória, 0 aedo é um adivinho do passado, como o adivinho o é do futuro".

Associada à memória mítica, os gregos, de acordo com Le Goff, desenvolveram técnicas de recordação que se introduzem no campo do direito e, mesmo, da retórica. Le Goff (1996, p. 442) assevera:

É necessário [...] não esquecer que ao lado da emergência espetacular da memória no seio da retórica, quer dizer, de uma arte da palavra ligada à escrita, a memória coletiva prossegue o seu desenvolvimento através da evolução social e política do mundo antigo.

Sempre interessou ao homem e, em especial, aos detentores do poder, conservarem, na memória do povo, seus grandes feitos, suas obras, comprovação disso se faz, por exemplo, através da estatuária. Ao mesmo tempo, a sociedade, em qualquer de suas camadas, procurou preservar costumes, lendas, tradições que a configuram. 0 indivíduo, sob este aspecto, não recorda sozinho, uma vez que 0 ato de recordar pode sofrer interferências pessoais e coletivas, determinando a conservação ou a omissão de um evento. Nesse sentido, Le Goff (1996, p. 426) esclarece:

Tornarem-se senhores da memória e do esquecimento é uma das grandes preocupações das classes, dos grupos, dos indivíduos que dominaram e dominam as sociedades históricas. Os esquecimentos e os silêncios da história são reveladores desses mecanismos de manipulação da memória coletiva. 
A memória ou 0 ato de recordar, individual ou coletivo, representa a preservação e, através dela, a releitura e 0 aprendizado dos costumes, das tradições, dos eventos políticos e sociais, das tragédias que identificam um indivíduo e a sociedade em que ele se insere. Neste aspecto, a memória se faz objeto de identidade, em que o ser humano, individual ou coletivamente, se reconhece e reconhece o outro como idêntico ou distinto. Por outro lado, a memória pode constituir-se em objeto de poder e manipulação social. Para tal faz-se necessário dominar-se o conhecimento dos seus mecanismos internos e externos de apreensão dos fatos e a manifestação das lembranças desses fatos por parte do memorialista, ou seja, a memória apresenta-se como objeto de estudos, constitui um corpus sob o qual se debruçam pesquisadores.

Convém destacar, porém, que, por vezes, ao longo da História oficial da humanidade, buscou-se 0 apagamento de fatos, circunstâncias, crenças. 0 exemplo mais candente desta tendência talvez esteja no Holocausto, imagem que ainda tinge de negro a História recente. Assim posto, à memória e a sua conservação deve-se a construção daquilo que, hoje, conhecemos como identidade, independente da classe social que ocupamos, da religião que professamos, dos conhecimentos técnicos que dispomos, nossa condição cidadã, ela está no âmago da preservação daquilo que nos constitui como sociedade.

0 pesquisador francês, Le Goff, acompanha, em seus estudos, a evolução histórica da memória e evidencia o crescente interesse a respeito do fenômeno mnêmico. Le Goff (1996, p. 439) informa que os primeiros estudos sobre a memória foram empreendidos por pensadores gregos e complementa que, para Platão e Aristóteles, "a memória é uma componente da alma, não se manifesta contudo ao nível da sua parte intelectual mas, unicamente, da sua parte sensível". A memória ficaria restrita à emoção, aos sentimentos individuais, não se registrando, na concepção daqueles estudiosos, qualquer relação entre a memória, componente espiritual do indivíduo, e a história social de um povo.

As relações que se estabelecem entre a memória do indivíduo e a sociedade em que ele se insere despertaram 0 interesse de diferentes áreas do saber; alguns estudos restringem-se ao indivíduo, posto isoladamente; outros, entretanto, consideram a interlocução que se faz entre 0 sujeito que rememora e a sociedade em que ele atua. Henri Bergson, em seu livro Matéria e M emória, por exemplo, dedicou-se à análise da memória individual, concebida como a conservação do passado que se mantém intacto no cérebro do indivíduo. Halbwachs e Bartlett dedicaram suas pesquisas às influências que o meio impõe àquele que recorda. 


\subsection{BERGSON: CONSIDERAÇÕES SOBRE A M EM ÓRIA INDIVIDUAL}

Bergson, no final do século XIX, estabeleceu distinções entre a memóriahábito e a lembrança propriamente dita. 0 pesquisador (s/d, p. 61) declara:

Estudo uma lição, e para aprendê-la de cor leio-a primeiramente escandindo cada verso; repito-a em seguida um certo número de vezes. A cada nova leitura efetua-se um progresso; as palavras ligam-se cada vez melhor, acabam por se organizar juntas [...].

A lembrança da lição, enquanto aprendida de cor, tem todas as características de um hábito [...], ela é adquirida pela repetição de um mesmo esforço.

Ao contrário, a lembrança de tal leitura particular, a segunda ou a terceira, por exemplo, não tem nenhuma das características do hábito. Sua imagem imprimiuse necessariamente de imediato na memória, já que as outras leituras constituem, por definição, lembranças diferentes.

Em consonância com as idéias de Bergson, a atenção e a repetição de gestos ou palavras determinam a aquisição da memória-hábito que se torna parte do adestramento cultural do indivíduo, dos ensinamentos sociais que ele recebe. A lembrança pura, quando se atualiza na imagem-lembrança, por outro lado, traz um momento ímpar na história de vida do indivíduo, pois possui data certa e se refere a uma situação definida.

Bergson ( $s / d, p .85)$ acresce as interferências que o meio pode determinar na lembrança individual e enfatiza que

as lembranças pessoais, exatamente localizadas, e cuja série desenharia o curso de nossa existência passada, constituem, reunidas, o último e maior invólucro de nossa memória. Essencialmente fugazes, elas só se materializam por acaso, seja porque uma determinação acidentalmente precisa da nossa atividade corporal as atraia, seja porque a indeterminação mesma dessa atitude deixe o campo livre ao capricho de sua manifestação.

Considerando-se tais ponderações, a memória consistiria na conservação do passado, latente no indivíduo, mas que pode ser chamado pelo presente sob as formas da lembrança. Além das recordações pessoais despertadas pelo seu exterior, o indivíduo relembra acontecimentos sociais, históricos, transformações de cunho econômico que, de alguma forma, marcaram a sua vida em sociedade. Determinar em que medida as lembranças do sujeito que rememora são influenciadas pelo meio em que ele viveu, pelas pessoas com quem ele convive e conviveu, representou uma das tarefas do estudo desenvolvido por Maurice Halbwachs, que estudou a memória como fenômeno histórico-social. Frederic Charles Bartlett, por sua vez, procurou demonstrar os vínculos que relacionam a lembrança individual e a sociedade na qual o memorialista atua, destacando para tal as influências culturais e ideológicas que condicionam esse recordar. 


\subsection{A M EM ÓRIA COLETIVA: OS ESTUdOS DE HALBWACHSE BARTLETT}

De acordo com os estudos de Halbwachs, a memória do indivíduo é reforçada pela sua interação com o meio: família, escola, profissão. 0 sujeito que recorda, nesta concepção, sofre ainda a interferência dos meios de comunicação de um modo geral. 0 estudioso (1990, p. 26) assevera que

nossas lembranças permanecem coletivas, e elas nos são lembradas pelos ou-
tros, mesmo que se trate de acontecimentos nos quais só nós estivemos envolvi-
dos, e com objetos que só nós vimos. É porque, em realidade, nunca estamos sós
[...]: porque temos sempre conosco e em nós uma quantidade de pessoas que
não se confundem.

As pesquisas de Halbwachs concedem, assim, relevância àqueles que fazem parte do círculo de convivência do indivíduo, os quais assumem papel importante na formação sócio-cultural daquele que recorda. Para Halbwachs (1990, p. 27), "eles me ajudam a lembrá-las (...) e encontro em mim muito das idéias e modos de pensar a que não teria chegado sozinho, e através dos quais permaneço em contato com eles". A memória do indivíduo, assim concebida, não é um processo solitário, resulta da interação social, a qual permite a construção de uma memória mais ampla, representada pela memória da própria sociedade na qual o indivíduo se faz presente.

Halbwachs (1990, p. 81-82) adverte, porém, que a memória coletiva trata-se de "uma corrente de pensamento contínuo, de uma continuidade que nada tem de artificial, já que retém do passado somente, aquilo que ainda está vivo ou capaz de viver na consciência do grupo que a mantém". Assim, quando as recordações do grupo distanciam-se no tempo e no espaço, sendo possível recuperá-las somente através de documentos escritos, a memória coletiva transforma-se em História. De acordo com o pesquisador (1990, p. 80), a História é

a compilação dos fatos que ocuparam o maior espaço na memória dos homens. $M$ as lidos em livros, ensinados e aprendidos nas escolas, os acontecimentos passados são escolhidos, aproximados e classificados conforme as necessidades ou regras que não se impunham aos círculos de homens que deles guardaram por muito tempo a lembrança viva.

Ecléia Bosi, em estudo realizado a respeito da memória dos velhos, retoma as pesquisas de Bergson e Halbwachs, acrescendo-Ihes as idéias defendidas por Bartlett. Bosi (1994, p. 64) afirma que se deve ao pesquisador

a utilização de um conceito-chave para conectar o processo cultural de um dado momento histórico ao trabalho da memória: o conceito de 'convencionalização' [...], Bartlett postula que a 'matéria-prima' da recordação não aflora em estado 
puro na linguagem do falante que lembra; ela é tratada, às vezes estilizada, pelo

ponto de vista cultural e ideológico do grupo em que o sujeito está situado.

Assim, tanto Halbwachs quanto Bartlett esforçam-se para demonstrar a relevância do círculo social, das questões político-econômicas, das tradições e dos costumes, enfim, dos interesses do grupo, no processo que desencadeia a recordação.

A memória, pois, de ordem individual e/ ou social resulta da intervenção de diferentes mecanismos que fazem aflorar lembranças, conservar tradições e costumes, conformar, sob determinados aspectos, a própria identidade cultural de um povo, inicialmente, sob a ótica popular, para, ao final do processo constituir História e, então, adquirir status de cultura erudita.

\section{UMA QUestão IDENTITÁRIA: CULTURA ERUdTA E CULTURA POPULAR}

De origem latina - idem - , a palavra identidade significa o mesmo, derivando-se daí as noções de homogeneidade, uniformidade, igualdade. Assim compreendido, identificar-se significa encontrar caracteres que aproximem 0 indivíduo dos seus semelhantes. Diante desta concepção, faz-se supor a existência do outro - o semelhante - alter - , ou seja, a identidade individual se define em relação ao outro. Referindo-se à questão identitária, Ricouer (1991, p. 424-425) afirma que

a identidade de um indivíduo ou de uma comunidade é responder à questão: Quem fez tal ação? Quem é o seu agente, seu autor? Essa questão é primeiramente respondida nomeando-se alguém, isto é, designando-o por um nome próprio. Mas qual é o suporte da permanência do nome próprio? Que justifica que se considere 0 sujeito da ação, assim designado por seu nome, como 0 mesmo ao longo de toda uma vida, que se estende do nascimento à morte? $\mathrm{A}$ resposta só pode ser narrativa. Responder à questão 'quem?', como o dissera Hannah Arednt, é contar a história de uma vida. A história narrada diz o quem da ação. A identidade do quem é apenas, portanto, uma identidade narrativa [...].

A noção de identidade narrativa mostra ainda sua fecundidade no fato de que ela se aplica tanto à comunidade quanto ao indivíduo. Podemos falar da ipseidade de uma comunidade [...]: indivíduo e comunidade constituem-se em sua identidade ao receberem tais narrativas, que se tornam para um e outro sua história efetiva.

Se a identidade constitui uma narrativa, Literatura e História representam, no construto social de uma nação, narrativas que unem um grupo de indivíduos, os quais compartilham costumes e tradições próprias que, primeiramente, foram conservadas pelas histórias populares, narrativas que se perpetuaram entre familiares, amigos, grupos sociais.

O Brasil, por exemplo, conforme da Matta (1986, p. 11-12), é 
cultura, local geográfico, fronteira e território reconhecidos internacionalmente, e também casa, pedaço de chão calçado com o calor de nossos corpos, lar, memória e consciência de um lugar com o qual se tem uma ligação especial, única, totalmente sagrada [...].

Ortiz (1994), contudo, destaca a diversidade regional que compõe o país e salienta aspectos culturais, econômicos, políticos caracterizadores desta diversidade. Na concepção do estudioso, a identidade nacional constitui-se, portanto, não só de elementos comuns a toda nação, mas também de inúmeras diferenças. Esta diversidade regional ressaltada pelo pesquisador foi apreendida pela Literatura, a partir do movimento romântico, que, no entanto, caracterizou-se pela ereção de figuras míticas, que ocupavam espaços distintos, mas que repetiam qualidades físicas e comportamentais. Segundo Bernd (1992, p. 18), a Literatura

que se atribui a missão de articular o projeto nacional, de fazer emergir os mitos fundadores de uma comunidade e de recuperar sua memória coletiva, passa a exercer somente a função sacralizante [...]. No Brasil, o Romantismo realizou uma revolução estética que, querendo dar à literatura brasileira o caráter de literatura nacional, agiu como força sacralizante [...] trabalhando somente no sentido da recuperação e da solidificação de seus mitos.

O M odernismo, por sua vez, atuou de forma dessacralizante e representou uma abertura em relação à diversidade que caracteriza a nação, a cultura do povo, as crenças populares foram revisitadas e passaram a integrar-se ao universo erudito. Bernd (1992, p. 18) acresce que

recentemente a literatura brasileira começa a operar a síntese - ainda inacabada - deste jogo dialético, associando o resgate dos mitos à sua constante desmitificação, o redescobrimento da memória coletiva a um movimentar contínuo dos textos, o que equivale a um perseverante questionamento de si mesma.

Assim posto, a Literatura dita culta tem, ao longo dos anos, participado da caracterização e fixação das marcas que definem uma possível identidade nacional, processo que se inicia nos anos subseqüentes à Independência e que encontra respaldo nos ideais românticos que então vigoravam. Acresce questionar em que medida a cultura popular atua neste processo e qual o papel desenvolvido pelas atividades dos teatros mambembes, no interior do país, para que configuremos o perfil desta identidade, se ela, de fato, pode assim sê-lo.

\section{Teatro: CONSIDERAÇões TEÓRICAS}

0 teatro, manifestação artística que se faz presente, no mundo ocidental, desde a civilização grega, é assim definido por Magaldi (2006, p. 7): “A palavra teatro abrange ao menos duas acepções fundamentais: o imóvel em que 
se realizam espetáculos e uma arte específica, transmitida ao público por intermédio do autor". Magaldi prossegue suas considerações e pondera: "No teatro, público e ator estão um em face do outro, durante o desenrolar do espetáculo" (2006, p. 7).

Diante da segunda idéia expressa pelo autor, faz-se evidente que, no teatro, acontece a interação entre o público e 0 ator; interação que é mediada por um texto, o texto dramático. Magaldi $(2006$, p. 8) acrescenta: "É preciso que um ator interprete um texto para o público, ou, se se quiser alterar a ordem, em função da raiz etimológica, o teatro existe quando o público vê e ouve 0 ator interpretar um texto".

Referindo-se à origem do teatro, M oisés (2001, p. 121) anota:

Identificado com práticas religiosas e mágicas, e mesclado com a dança, a música e o canto, o teatro despontou com a própria história num tempo infenso a demarcações [...] a gênese do teatro mergulha num passado insondável, região brumosa onde se esboçaria o próprio nascedouro da Arte. Inócuo, portanto, sondar a proto-história do teatro: sua trajetória efetiva, que compreende o lapso de tempo suscetível de precisão, graças aos documentos existentes, principia em solo grego, aproximadamente no século $\mathrm{VI}$ a.C.

Conforme nos legou a tradição, os primeiros registros acerca das manifestações teatrais encontram-se em solo helênico, no culto ao Deus Baco, ou Dioniso e é deste teatro que se ocupa Aristóteles em sua Poética, ao analisar longamente a tragédia: "de tragoidia, canto de bode" (M OISES, 2001, p. 121).

Ao acompanhar a evolução do teatro, Moisés (2001, p. 122) destaca que, ao longo da Idade Média, as manifestações teatrais

entraram em ostracismo, de que foram despertadas após o século XIII, com 0 aparecimento de farsas, mimos, arremedilhos e outras expressões do teatro cômico, e após a Renascença, com a redescoberta da Antiguidade clássica. De lá para cá, sofrendo toda sorte de vicissitudes e de altos e baixos, o teatro tem-se mantido como uma das mais ricas e atuantes expressões artísticas.

Convém salientar, porém, que, a par do teatro dito clássico e tido como pagão pela Igreja Católica durante a Idade Média, desenvolveu-se uma nova modalidade teatral em que as companhias se apresentavam de cidade em cidade, tratava-se do teatro itinerante. Os artistas da época, os saltimbancos,

andavam em carroças, sempre em grupos, chamadas trupes, e não tinham morada certa. Hoje, esse teatro itinerante também é conhecido como teatro mambembe. Perseguidos pela Igreja e tratados como fora-da-lei, os saltimbancos começaram a usar máscaras para não serem reconhecidos. Uma tradição que 
descende diretamente desses artistas é o circo, que até hoje percorre as cidades apresentando seus números ${ }^{2}$.

No Brasil, o teatro chegaria, nos anos posteriores ao descobrimento, através dos jesuítas e seu propósito catequético. Segundo Magaldi (2001, p. 16):

As primeiras manifestações cênicas no Brasil cujos textos se preservaram são obra dos jesuítas, que fizeram teatro como instrumento de catequese [...], uma aplicada composição didática de quem tinha um dever superior a cumprir: levar a fé e os mandamentos religiosos à audiência, num veículo ameno e agradável, diferente da prédica seca dos sermões.

Magaldi (2001, p. 17-18) anota a importância do teatro anchietano e escreve:

Todo o universo religioso, presente na dramaturgia medieval, se estampa nas oito obras mais caracteristicamente teatrais conservadas do canarino [...]. A dicotomia fundamental da Idade Média persiste nos autos jesuíticos: defrontam-se [...] o bem e o mal, os santos, anjos e outros nomes protetores da Igreja com as forças demoníacas, corte variada de diabos ostentando nomes de índios inimigos.

Entre as encenações promovidas pelos jesuítas e o surgimento do teatro brasileiro propriamente dito, em pleno Romantismo, registra-se apenas a produção de Manoel Botelho de Oliveira, segundo Magaldi (2001, p. 25), "considerado o primeiro comediógrafo brasileiro". O pesquisador adverte: "Nenhuma boa vontade, contudo, nos autoriza a incluir o autor em nossa literatura dramática" (2001, p. 25). E, embora conceda relevância histórica ao teatro de Gonçalves de Magalhães, o estudioso considera Martins Pena, autor de "O juiz de paz na roça", como o introdutor do teatro em nossa cultura. Magaldi (2001, p. 25) assevera:

Poucos, talvez, na ocasião [1838], assinalassem o significado do acontecimento. Começava aí, porém, uma carreira curta e fecunda [...] e o verdadeiro teatro nacional, naquilo que ele tem de mais específico e autêntico. Martins Pena é o fundador da nossa comédia de costumes, filão rico e responsável pela maioria das obras felizes que realmente contam na literatura teatral brasileira.

Magaldi (2001, p. 53) prossegue suas reflexões e analisa diferentes peças teatrais escritas pelo autor. A seguir, conclui:

Escrevendo para o riso imediato da platéia, sem a procura de efeitos literários mais elaborados, Martins Pena revelou inteira a sua fisionomia cômica [...]. Tudo é simples na comédia de Martins Pena - a situação, o traço dos numerosos ti-

2 Disponível em: http://www.tguaira.pr.gov.br/tguaira/modules/conteudo_historia/conteudo _historia.php?conteudo_historia=27. Acesso em: 8 set. 2007. 
pos, o desenvolvimento da trama, a conversa das personagens [...]. A intriga escorre, assim, fluída, vibrante, e as peripécias, para chegarem ao desfecho, são maquinadas à vista do espectador, reclamando desde logo a sua cumplicidade e simpatia.

0 teatro seria uma modalidade amplamente contemplada pelos prosadores românticos, entre os quais se destacam Gonçalves Dias, Joaquim Manoel de Macedo e José de Alencar. Sobre os realistas, Magaldi (2001, p. 125) pondera: "as peças de Machado de Assis (1839-1908) não apresentam grandes qualidades em si. Tivesse 0 autor cultivado apenas o teatro, seu nome seria absolutamente secundário na literatura brasileira". Diversos nomes destacam-se entre o crepúsculo do século XIX e o surgimento do século XX: França Júnior, Artur Azevedo, Coelho Neto e outros. Por fim, entre os modernistas de primeira hora, Magaldi (2001, p. 203) faz referência ao trabalho de Oswald de Andrade: "[...] sentimos que as incursões teatrais de Oswald de Andrade, um dos grandes nomes da Semana de Arte Moderna (1890-1954), tenham dormido nos livros, sem nunca passarem pela prova do palco".

Fixando seus estudos nas manifestações do moderno teatro brasileiro, posterior a década de 1930, Prado (2003, p. 15) registra:

As representações efetuavam-se à noite, sem descanso semanal, em duas sessões, às 20 e 22 horas, afora as vesperais de domingo. As companhias, sobretudo as de comédia [...] trocavam de cartaz com uma freqüência que causaria espanto às gerações atuais, oferecendo não raro uma peça diversa a cada semana.

0 pesquisador revela ainda que: "A orientação geral do espetáculo cabia ao ensaiador" (PRADO, 2003, p. 16), que se envolvia com a mecânica cênica desde os móveis e utensílios colocados no palco, passando pela marcação dos papéis e a movimentação, em cena, os atores.

Os cenários, a não ser quando se tratava de uma peça julgada de muito boa qualidade literária ou muito promissora em termos de bilheteria, confeccionavam-se a partir dos elementos pertencentes ao acervo da companhia, resquícios de encenações anteriores [...]. Quanto às roupas usadas em cena, se eram modernas [...], cabia aos atores fornecê-las, de modo que estes igualmente iam formando, ao longo dos anos, o seu pequeno cabedal artístico (PRADO: 2003, p. 17).

No que se refere aos atores, Prado (2003, p. 19/20) concede relevância à capacidade de improvisação dos grandes artistas; o estudioso anota ainda que a maioria das peças teatrais tinha o Rio de Janeiro como palco principal:

Organizado o repertório, entretanto, ou esgotada a curiosidade do público carioca pelo elenco, partia este normalmente em excursão, disposto a explorar em outras praças [...] o seu patrimônio dramático, constituído por uns tantos cenários e por cinco ou seis comédias semimemorizadas. À medida que a companhia se afastava do Rio, as peças, em geral já cortadas [...] para caber nas duas horas 
habituais de espetáculo, tendiam a se esfacelar. Aboliam-se os papéis menores, adaptavam-se outros conforme os recursos humanos disponíveis, substituíam-se artistas consagrados por outros de menor prestígio, aproveitavam-se amadores locais [...]. A partir de uma certa distância, antes cultural que espacial, as grandes companhias eram substituídas na tarefa de propagar o repertório pelos numerosos "ambembes" [...].

Legatário desta tradição do teatro itinerante, dotado de poucos recursos, mas de grande capacidade de improvisação cênica e voltado para a diversão do público, em 1929, surgia em Sorocaba, interior de São Paulo, o "Circo Teatro Nhô Bastião". Mais tarde, criava-se um pavilhão de zinco e o teatro assumia a denominação de "Politeama Oriente", sob o comando de José Epaminondas de Almeida.

Analisando as manifestações teatrais do período, mais especificamente, entre 1930 e 1932, Prado (2003, p. 20) salienta:

Se nossa forma era a do teatro itinerante, como objetivo não havia praticamente outro senão divertir, ou seja, suscitar o maior número de gargalhadas no menor espaço de tempo possível. 'Rir! Rir! Rir!'- prometiam não só modestos espetáculos do interior mas também a publicidade impressa nos jornais pelas companhias mais caras do país.

Prado (2003, p. 20/21) ainda acrescenta:

0 ator cômico vinha assim se colocar, sem que ninguém sequer lhe disputasse esse direito, no centro do teatro nacional. 0 que se exigia dele, de resto, não era tanto preparo técnico, recursos artísticos extraordinários, versatilidade, e sim, ao contrário, que se mantivesse sempre fiel a uma personalidade, a sua, naturalmente engraçada e comunicativa.

Sob a égide da alegria e da diversão, o pavilhão de zinco da família Almeida adentrou o Rio Grande do Sul em 1962, então sob o comando de José M aria de Almeida, filho mais velho de José Epaminondas, e que adotou o nome artístico de Serelepe. 0 grupo dissolveu-se em 1981, em face das dificuldades financeiras, e parte da família fixou residência em Curitiba (PR), de onde partia para excursões breves que incluíam até dois espetáculos por dia em cidades diferentes. 0 Teatro de Lona Serelepe renasceria, com a estrutura física de um circo, em 1994, sob o comando de Marcelo Benvenuto de Almeida, filho de José Maria, que adotou, a exemplo do pai, o nome Serelepe.

\section{Teatro de Lona Serelepe}

Uma das últimas companhias de teatro mambembe em atividade no Brasil, o Teatro de Lona Serelepe tem enfrentado inúmeras adversidades, num grupo, hoje, formado basicamente pela família Benvenuto de Almeida. 
Conforme Lea Benvenuto de Almeida [esposa de José Maria], uma das mais experientes do grupo [...], são mais de trinta envolvidos diretamente com o espetáculo, entre artistas e pessoas que colaboram com a montagem do teatro, que fica em torno de um mês e quinze dias em cada município.

0 teatro funciona como uma cooperativa, todo mundo trabalha e tem participação nos lucros e também nos prejuízos ${ }^{3}$.

Alguns membros da família separam-se do grupo, por exemplo, para completar os estudos em nível superior. Há aqueles também que, por questões financeiras, seguiram outras profissões e fixaram residência em diferentes pontos do estado. 0 vínculo familiar, apesar disso, é evidente desde o primeiro contato. Laços fraternos também unem aqueles que acompanham a família: senhoras, jovens que deixaram seus parentes, suas casas e optaram pela vida em trailers, caminhões e ônibus adaptados como residência.

Entre os elementos que compõem o grupo teatral, a memória parece reservada a Lea Benvenuto, contra-regra do teatro, que se permite devanear num caminhão baú destinado ao figurino e às peças cenográficas. Lea relembra a origem familiar, as dificuldades enfrentadas pelo pai, dono de circo, recorda o preconceito enfrentado em inúmeras ocasiões e sorri ao rememorar o nascimento dos filhos e dos netos.

0 transporte difícil, o aluguel de casas que abrigassem as famílias no período em que permaneciam nas diversas cidades, a freqüência dos menores às escolas, os acidentes em cena e fora do palco fazem parte deste universo que a contra-regra recorda. À memória do grupo vincula-se a memória individual, os sonhos da adolescente, as frustrações da mulher madura, o amor pelo teatro. Neste momento, reaparecem aqueles que povoaram a sua existência: homens e mulheres que, em algum momento de suas vidas, levaram o riso ou 0 pranto, a comédia, o drama ou a música para espectadores de idades diferentes.

Ao recompor, nestes devaneios, a história do teatro propriamente dita, Lea Benvenuto relata que a freqüência à escola por parte dos membros do teatro somente foi regulamentada em 1978; destaca também que, até aquela data, a profissão não era regulamentada, obrigando as mulheres do grupo a trabalharem com a mesma documentação exigida para as prostitutas.

Outro fato que se sobreleva nestas reminiscências diz respeito ao período ditatorial, vivido pelo Brasil entre 1964 e 1985, e a dificuldade para encenar peças consideradas "impróprias" pelos censores que variavam nas diferentes cidades visitadas pelo teatro. Além da censura prévia, havia o risco iminente de uma censura presencial, enquanto os atores estivessem no palco. José Maria

3 Disponível em: http://www.farrapo.com.br/jc/?num=002059\&ag-jc. Acesso em: 9 set. 2007. 102

A Cor das Letras - UEFS, n. 9, 2008 
de Almeida, o velho Serelepe, relembra que ao palhaço era concedido o espaço do riso, desde que não houvesse palavras de baixo calão ou dúbias. José M aria destaca, porém, que jamais teve seu trabalho, em cena, cerceado e alegra-se, ao salientar que o dom de fazer rir dispensava, naqueles tempos, 0 deboche, o escracho.

Atualmente, revezam-se, no palco, quatro gerações da família em diversificadas apresentações, uma vez que o grupo possui um repertório de, aproximadamente, setenta espetáculos montados entre dramas, altas comédias, chanchadas, revistas e peças infantis. Diante das primeiras entrevistas realizadas, no entanto, verifica-se que a conservação da cultura dita erudita e que se configura, no caso da encenação teatral, em peças como "Romeu e Julieta", "0 ébrio", "A paixão de Cristo", já figurou como foco principal das apresentações do grupo teatral. Entretanto, a modernidade, a concorrência da televisão exigiram um novo formato que privilegia a piada cotidiana, a malícia que envolve 0 espectador.

Há experiências mencionadas pelo grupo em que dramas foram cancelados pela falta de público. Um dos exemplos mais candentes desta tendência, segundo Lea, teria acontecido numa cidade da fronteira oeste do Rio Grande do Sul, em que o drama "A paixão de Cristo", ensaiado exaustivamente, teve sua exibição suspensa na quarta e na quinta-feira que antecediam à Semana Santa em face da baixa venda de ingressos. Na sexta-feira santa, contudo, 0 grupo teatral encenou "Tudo em cima da cama", peça com título subjetivo e de dupla interpretação, em que um casal discute, em cima da cama, sua relação afetiva, e o teatro teve lotação esgotada. Ao comentar este fato, Marcelo Serelepe credita a preferência pela comédia às dificuldades de cunho socioeconômico enfrentadas pela população que busca, no teatro, uma forma de prazer ameno, sem grandes elaborações de ordem ideológica que lhe permita, por algumas horas, gozar da "terapia do riso" - título atribuído ao palhaço que Marcelo encarna.

\section{CONSIDERAÇÕES FINAIS}

O ser humano, ao longo de sua existência, tem lançado mão de elementos que permitam a perpetuação dos seus feitos e dos fatos sociais em que se envolveu. A literatura culta, nesse período, tem sido instrumento relevante para a fixação de idéias, tradições, costumes que se eternizam sob a ótica de um grupo dominante. Constitui desafio ao pesquisador, egresso do curso de Letras e, portanto, com formação basicamente de ordem erudita, adentrar em um universo que privilegia as histórias populares. Tal universo é rico em experiências humanas, ao mesmo tempo, em que propicia recompor-se, a partir 
dele, parte da memória coletiva de nosso povo - independente do poder financeiro, político, religioso que a determina.

Devem desnudar-se, ao longo do trabalho, diferentes momentos históricos e o impacto que ações políticas impuseram a nossa gente. Ao mesmo tempo, espera-se que seja possível, (re) conhecer as histórias de vida daqueles que transitam pelo estado, pelas pequenas cidades e delas colhem anedotas, cantigas, momentos trágicos, grandes amizades.

0 trabalho em pauta encontra-se em sua fase inicial, e ainda carece da coleta de material pertinente em outras companhias, mas se propõe a recompor a memória da cultura popular através de sujeitos dispostos a rememorar e, de modo concomitante, levar a diversão ao público que, nesta alegria, nesta interação, recorda e constitui história, memória coletiva que configura as nossas crenças, os nossos costumes, os valores morais que nos pautam.

\section{REFERÊNCIAS}

BERGSON, H. Matéria e memória. São Paulo: Martins Fontes, s/d.

BERND, Z Literatura e identidade nacional. Porto Alegre: EdUFRGS, 1992.

BOSI, E. Memória e sociedade: lembrança de velhos. 3. ed. São Paulo: Cia. das Letras, 1994.

HALBWACHS, M. A memória coletiva. São Paulo: Vértice, 1990.

LE GOFF, J. História e memória. 4. ed. Tradução de Leitão. Campinas: Ed. UNICAMP, 1996.

MAGALDI, S. Iniciação ao teatro. São Paulo: Ática, 2006.

MAGALDI, S. Panorama do teatro brasileiro. 5. ed. São Paulo: Global, 2001.

M OISES, M. A criação literária Prosa II. São Paulo: Cultrix, 2001.

0 TEATRO no mundo. Centro cultural Teatro Guairá. Curitiba (PR): 2007. Disponível em: http://www.tguaira.pr.gov.br/. Acesso em: 8 set. 2007.

PRADO. D. A. 0 teatro brasileiro moderno. 2. ed. São Paulo: Perspectiva, 2003.

RICOUER, P. 0 si-mesmo como um outro. Trad. Lucy M oreira Cesar. Campinas: Papirus, 1991.

TEATRO de lona Serelepe é sucesso em Caçapava. Jornal de Caçapava. Caçapava do Sul (RS), 16. Nov. 2006. Disponível em: http://www.farrapo.com.br/jc/?num=002059\&ag-jc. Acesso em: 9 set. 2007. 